\title{
Microstructural and mechanical characteristics of laser welding of Ti6Al4V and lead metal
}

\author{
Shusen Zhao ${ }^{\mathrm{a}, \mathrm{b}, *}$, Gang Yu ${ }^{\mathrm{b}}$, Xiuli $\mathrm{He}^{\mathrm{b}}$, Yaowu $\mathrm{Hu}^{\mathrm{b}}$ \\ a Laboratory of All-Solid-State Laser Sources, Institute of Semiconductors, Chinese Academy of Sciences, No. A35, QingHua East Road, Haidian District, Beijing 100083, China \\ ${ }^{\mathrm{b}}$ Key Lab of Mechanics in Advanced Manufacturing, Institute of Mechanics, Chinese Academy of Sciences, 15 Beisihuanxi Road, Haidian District, Beijing 100190, China
}

\section{A R T I C L E I N F O}

\section{Article history:}

Received 19 November 2011

Received in revised form 5 February 2012

Accepted 21 February 2012

Available online 1 March 2012

\section{Keywords:}

Laser welding

Welding of different materials

Interfaces

Microstructure

Mechanical properties

\begin{abstract}
A B S T R A C T
Titanium alloy Ti6Al4V and lead metal were welded using a continuous wave Nd:YAG laser. The influences of laser power, scanning velocity, and laser beam offset on weld morphology were investigated. Microstructure, chemical composition and mechanical properties of the joints were evaluated. Experimental results showed that fusion weld formed at the upper part of the weld and brazing weld with solder of $\mathrm{Pb}$ formed at the lower part of the weld under appropriate process condition. Interfaces were formed between mixed fusion zone and liquid lead zone in molten pool during laser welding of Ti6Al4V and lead. Reasons for interface formation may be different driving force of various regions in molten pool, and the miscibility gap of $\mathrm{Ti}$ and $\mathrm{Pb}$ binary system. $\mathrm{Ti}-\mathrm{Pb}$ intermetallic compound $\mathrm{Ti}_{4} \mathrm{~Pb}$ was detected at the fusion weld zone, which made the microhardness of the weld seam was higher than that of the base materials. The strength of the joint was at least equal to or larger than that of lead base material.
\end{abstract}

(c) 2012 Elsevier B.V. All rights reserved.

\section{Introduction}

As one of the new joining technologies, laser welding has recently received growing attention because of its special features and potential. Laser welding has many benefits in comparison with conventional thermal joining processes. The primary advantages include high scanning velocity, narrow heat-affected zone (HAZ), low distortion, excellent controllability and the ability to produce a high-intensity heat source, which is suitable for precision welding. Grigor'yants (1987) established laser welding of aluminum alloy and lead by using a tin interlayer.

Some research about laser welding of titanium alloys and laser joining titanium alloys to other alloys has been carried out. Akman et al. (2009) used pulsed Nd-YAG laser welding technique to join Ti6Al4V plane sheets. Kreimeyer et al. (2005) presented a study for laser joining of aluminum-titanium in the butt joint configuration, including numerical simulation, process development, characterization of the seam morphology and mechanical properties. Chen et al. (2011) reported laser welding of Ti6Al4V and 5A06 aluminum alloy plates with a thickness of $1.5 \mathrm{~mm}$. The results indicated combination of rectangular spot laser welding-brazing and V-shaped groove could effectively control the fracture of $\mathrm{Ti} / \mathrm{Al}$ joints in the seam in a wide processing parameters window. Zhao et al. (2011)

\footnotetext{
* Corresponding author at: Building 1, Room 425, No. A35, QingHua East Road, Haidian District, Beijing 100083, China. Tel.: +86 10 82304946; fax: +861082304353 .

E-mail address: zhaoshusen@semi.ac.cn (S. Zhao).
}

used finite element method and processing experiments to investigate the thermal phenomenon and microstructure of laser overlap welding of Ti6Al4V and 42CrMo alloy steel.

With regard to the microstructure analysis of dissimilar metal joints by laser beam, an amount of numerical simulation and experiments were used to investigate the microstructure and mechanical properties of welded seam. Chung and Wei (1999) reported that the quality of dissimilar joint strongly depended on distribution of elements in molten pool. Marangoni convection of liquid metal in the molten pool was recognized as one of the important processes that determine the mass transport during welding process. A majority of studies on heat and mass transfer of laser dissimilar welding were based on the assumption that either a binary system with complete miscibility or little solubility between dissimilar metals. Phanikumar et al. (2004, 2005a,b) applied continuous $\mathrm{CO}_{2}$ laser welding between $\mathrm{Fe}-\mathrm{Cu}$ dissimilar couple in a butt-weld geometry at different process conditions. The experimental results presented a characterization of weld/base-metal interface. The iron side could grow into the weld with a local change in length scale, whereas the interface on the copper side indicated a barrier to growth. Tomashchuk et al. (2010) predicted the weld shape evolution, fluid flow and mixing pattern in dissimilar welds formed between copper-stainless steel couple with limited solubility by numerical simulation. Chakraborty and Chakraborty (2007) and Chakraborty (2009) studied the effects of turbulence on momentum, heat, and mass transfer during laser welding of a copper-nickel dissimilar couple without a miscibility gap by carrying out three-dimensional unsteady Reynolds Averaged Navier Stokes (RANS) simulations. Little work has been carried out to investigate the microstructure 
during laser welding of dissimilar materials with incomplete miscibility, such as Ti and $\mathrm{Pb}$.

Laser butt welding experiments were conducted using a highpower CW Nd:YAG laser to explore the weldability of Ti6Al4V titanium alloy and lead metal. Influence of process parameters on weld morphology was discussed. Microstructure, chemical composition and mechanical properties of the welded joint were also tested.

\section{Experimental procedures}

Ti6Al4V $(60 \mathrm{~mm} \times 20 \mathrm{~mm} \times 2 \mathrm{~mm}$; Fe $\leq 0.30, \mathrm{C} \leq 0.10, \mathrm{~N} \leq 0.05$, $\mathrm{H} \leq 0.015, \mathrm{O} \leq 0.15, \mathrm{Al}=5.5-6.8, \mathrm{~V}=3.5-4.5, \mathrm{Ti}=\mathrm{Bal}$. (wt.\%)) and lead $(60 \mathrm{~mm} \times 20 \mathrm{~mm} \times 2 \mathrm{~mm}$ ) plates were prepared for laser welding, which was conducted on a $1 \mathrm{~kW} \mathrm{Nd:YAG} \mathrm{laser} \mathrm{materials} \mathrm{process-}$ ing system with five-axis computerized numerical control (CNC) working station. The surfaces of the sheets were cleaned with acetone before experiments. $2.5 \mathrm{l} / \mathrm{min}$ flow of high purity argon gas was passed through the molten pool from top side to produce a shielding effect. The defocus distance was 0 and the diameter of laser spot was $0.113 \mathrm{~mm}$. Other process parameters of the experiments are given in Table 1. Laser beam offset in the table reflects the distance between the center of laser spot and the joint line. We consider the positive values of deviation at the titanium alloy side, and the negative values at the lead side.

Metallographic samples of the welded seam were prepared using standard mechanical polishing procedures. Ti6Al4V and lead were etched in $\mathrm{HF}: \mathrm{HNO}_{3}: \mathrm{H}_{2} \mathrm{O}$ solution in volume ratio of $2: 4: 100$ and $\mathrm{H}_{2} \mathrm{O}: \mathrm{CH}_{3} \mathrm{COOH}: \mathrm{HNO}_{3}$ solution in volume ratio of $16: 3: 4$, respectively. Microstructure of the welding seam was characterized by ZEISS EVO18 scanning electron microscopy (SEM) equipped
Table 1

Process parameters of laser welding experiments.

\begin{tabular}{lll}
\hline Laser power $(\mathrm{W})$ & Scanning velocity $(\mathrm{mm} / \mathrm{s})$ & Laser beam offset $(\mathrm{mm})$ \\
\hline 200 & 20 & -0.5 \\
200 & 20 & -0.25 \\
200 & 20 & 0 \\
200 & 20 & +0.25 \\
200 & 20 & +0.5 \\
250 & 25 & -0.5 \\
250 & 25 & -0.25 \\
250 & 25 & 0 \\
250 & 25 & +0.25 \\
250 & 25 & +0.5 \\
400 & 20 & +0.25 \\
\hline
\end{tabular}

with BRUKER Xflash 5010 energy dispersive spectrometer (EDS). Microhardness of the welded seam was measured by an automatic microhardness tester with a test load of $0.245 \mathrm{~N}$ and a dwelling time of $15 \mathrm{~s}$. The transverse tensile test was conducted with a universal testing machine at a cross-head speed of $5 \mathrm{~mm} / \mathrm{min}$ to evaluate the tensile strength of the joints. The breaking force was recorded when the specimen fractured.

\section{Results and discussion}

\subsection{Influence of process parameters on weld morphology}

Laser power density was a key factor during laser welding process. Welding mode would change to penetration mode from thermal-conductive mode, when laser power density exceeded a certain limit. Spot diameter of the laser beam was maintained at a constant of $0.113 \mathrm{~mm}$, so laser power density was only
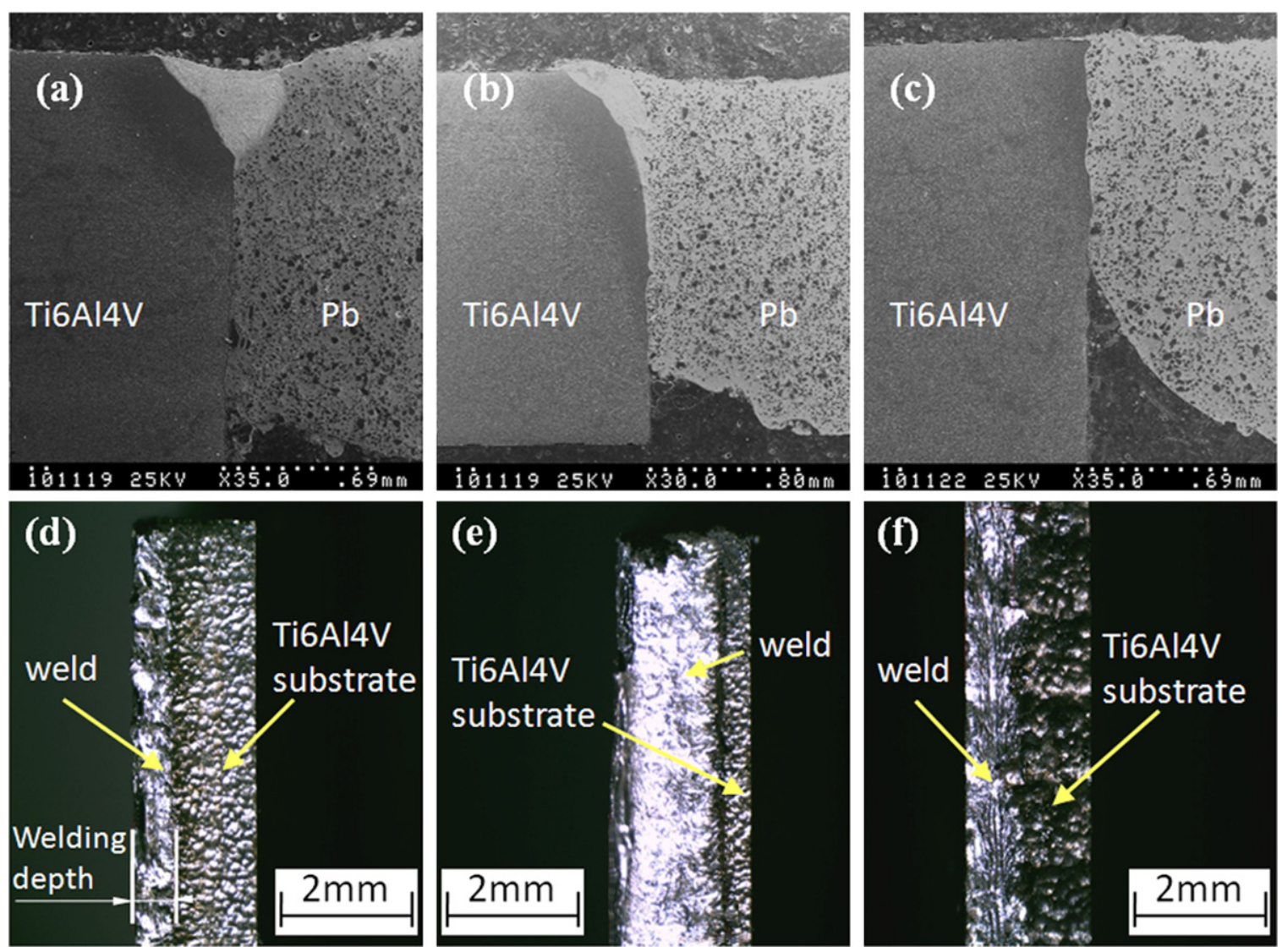

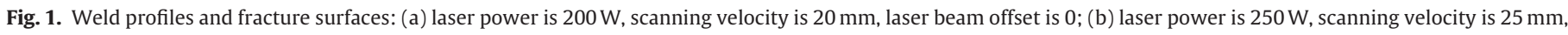
laser beam offset is 0; (c) laser power is $200 \mathrm{~W}$, scanning velocity is $20 \mathrm{~mm}$, laser beam offset is $-0.25 \mathrm{~mm}$; (d)-(f) fracture surfaces of (a)-(c), respectively. 


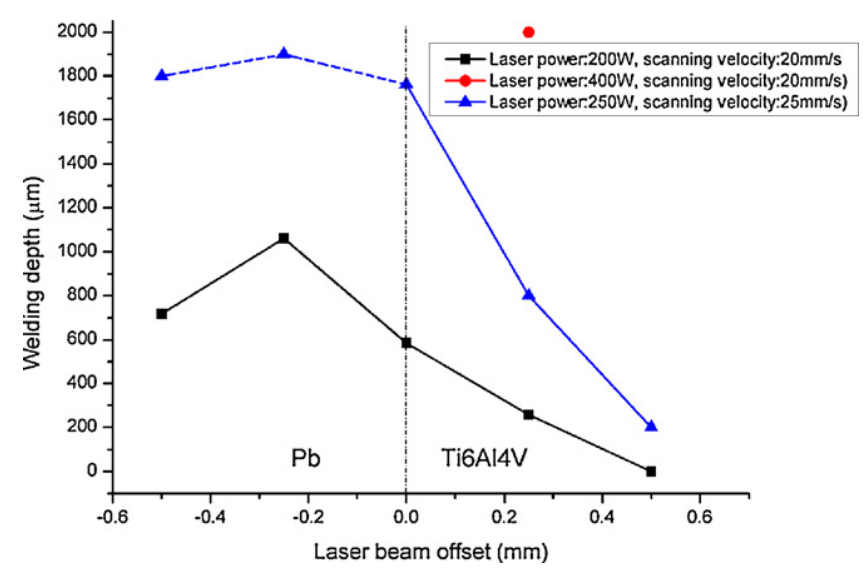

Fig. 2. Welding depth as a function of laser beam offset, laser power and scanning velocity.

dependent on the laser power value. In addition, titanium alloy and lead metal had different thermophysical properties, especially in melting point and heat conductivity properties. The asymmetry of the molten pool cannot be ignored. Thus, laser beam offset was another key factor to the welding quality.

There were four types of the weld morphology under the process conditions listed in Table 1 . The 1 st type was the thermalconductive weld formed by laser beam with lower power density locating on the center of the weld, shown in Fig. 1(a). The 2nd type was keyhole weld formed by laser beam with higher power density locating on the center of the weld, shown in Fig. 1(b). The 3rd type was brazing joint with laser beam locating on lead metal, shown in Fig. 1(c). The 4th type was penetration weld formed by laser beam with high laser power locating on Ti6Al4V, and this type of weld was described in detail in following section, shown in Fig. 9.

After process experiments, the joints were broken along the scanning direction, and the fracture surfaces could show the adhesion zone of molten lead on the titanium alloy along the whole welding length. The fracture surfaces of the welds shown in Fig. 1(a)-(c) are presented as Fig. 1(d)-(f), respectively. The welding depth is defined as the depth of adhesion zone perpendicular to the scanning direction, shown in Fig. 1(d).

The welding depth for different laser beam offset values, laser power and scanning velocities is shown in Fig. 2. Under the conditions of $200 \mathrm{~W}$ laser power and $20 \mathrm{~mm}$ scanning velocity, fusion welding seam formed when the laser beam was located at the center of the weld, shown in Fig. 1(a), and almost no welding seam was formed with positive laser beam offset values, shown in Fig. 3. When laser beam irradiated the lead substrate side, the titanium alloy almost remained solid state, and the lead material melted and wet the solid Ti6Al4V interface to form a brazing seam during welding process, shown in Fig. 1(c).

The similar tendency of welding depth was obtained under the conditions of $250 \mathrm{~W}$ laser power and $25 \mathrm{~mm} / \mathrm{s}$ scanning velocity, whereas a large volume lead metal was melted and evaporated when laser beam was located on lead substrate. Even molten lead might fall down in the form of droplet from the specimens by the shielding gas under condition of negative laser beam offset and $250 \mathrm{~W}$ laser power. For the failure welding processes, welding depth was unreasonable and marked with dotted line in Fig. 2.

When laser beam was located on the center of the weld, laser power was $250 \mathrm{~W}$, and scanning velocity was $25 \mathrm{~mm} / \mathrm{s}$, the welding depth reached $1.763 \mathrm{~mm}$ close to the thickness of the specimen, shown in Fig. 1(b). Compare weld morphology of Fig. 1(a) and (b), the welding processes had the same linear energy defined as a ratio of laser power to scanning velocity, but significant differences in weld profiles. The depth-width ratio is defined as the ratio of

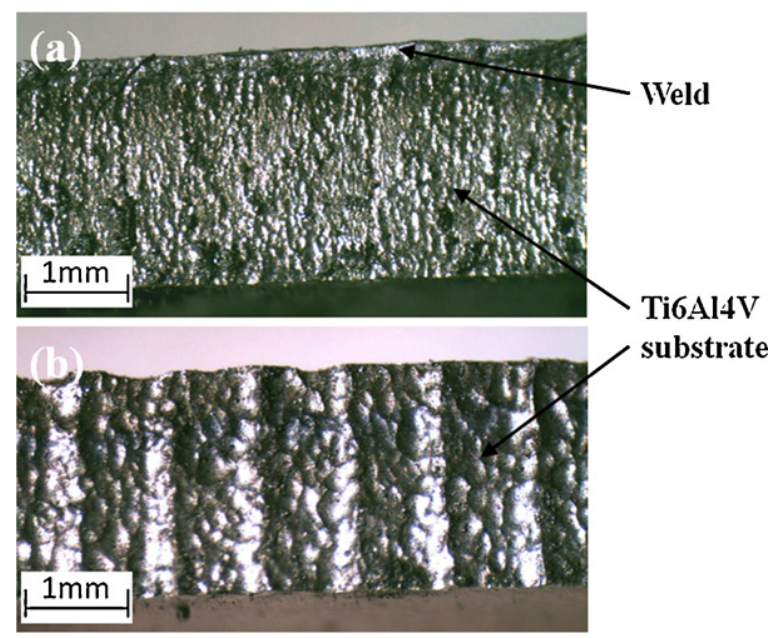

Fig. 3. Fracture surfaces: (a) laser power is $200 \mathrm{~W}$, scanning velocity is $20 \mathrm{~mm}$, laser beam offset is $0.25 \mathrm{~mm}$ and (b) laser power is $200 \mathrm{~W}$, scanning velocity is $20 \mathrm{~mm}$, laser beam offset is $0.5 \mathrm{~mm}$.

welding depth to welding width of the welds. The influence of power density on the depth-width ratio is shown in Table 2.

The depth-width ratio of the welds increased with increasing laser power density. Under condition of lower power density, laser welding was performed in the thermal conductive mode. The material was melted and a hemispherical weld was formed similarly to conventional fusion welding processes, thus the depth-width ratio of the weld was relatively small. With the higher power density, the laser energy density exceeded a certain limit to initiate local vaporization. The material was not only melted, but also evaporated, and the reaction force of the evaporated metal gas increased rapidly. Vibration and deformation of the liquid surface became large due to the increased vapor pressure. Then a keyhole was formed in the molten pool, and the material was heated directly by the laser beam through the keyhole, presented by Fabbro et al. (2005). Thus higher weld depth-width ratio was achieved for a higher power density. It could be seen form Fig. 2 that keyhole was also produced with laser power of $400 \mathrm{~W}$, scanning velocity of $20 \mathrm{~mm} / \mathrm{s}$, and offset of $0.25 \mathrm{~mm}$. The specimen with $2 \mathrm{~mm}$ thickness had been penetrated.

\subsection{Microstructure and chemical composition of weld}

Ti6Al4V is a $\alpha+\beta$ titanium alloy. The crystal structure changes from $\alpha$ (hcp, hexagonal close-packed) to $\beta$ (bcc, body-centered cubic) when the temperature exceeds to $995^{\circ} \mathrm{C}$. The microstructure of Ti6Al4V parent metal shown in Fig. 4(d) consisted of two phases: intergranular $\beta$ phase (white) in equiaxed $\alpha$ phase (black). Fig. 4(a) shows the microstructure in the HAZ of Ti6Al4V. The HAZ near the fusion line contained a number of acicular martensite due to the relatively high temperature in the thermal cycle process. This phenomenon was similar to the result of laser welding titanium alloy to steel presented by Zhao et al. (2011).

Line scan of the weld was carried out. The elements distribution of $\mathrm{Ti}$ and $\mathrm{Pb}$ are shown in Fig. 5. It could be seen from the diagram that both $\mathrm{Pb}$ and Ti elements were detected in the white weld region which indicated that both titanium alloy and lead were melted to form a fusion welding seam. Fig. 4(b) shows the enlarged diagram of the white weld region. From the picture, the weld was composed of sand particle-like microstructure. EDS analysis was carried out on white weld seam region in Fig. 4(b) to evaluate the chemical composition. EDS spectrum and chemical composition are shown in Fig. 6 and Table 3, respectively. As illustrated in the table, the content of $\mathrm{Ti}$ and $\mathrm{Pb}$ elements in weld region was consistent with the line scan result. 
Table 2

Depth-width ratio for different power density.

\begin{tabular}{|c|c|c|c|c|}
\hline Power $(\mathrm{W})$ & Scanning velocity $(\mathrm{mm} / \mathrm{s})$ & Linear energy $(\mathrm{J} / \mathrm{m})$ & Power density $\left(\mathrm{W} / \mathrm{cm}^{2}\right)$ & Depth-width ratio \\
\hline 200 & 20 & $10^{4}$ & $1.995 \times 10^{6}$ & 1.07 \\
\hline 250 & 25 & $10^{4}$ & $2.494 \times 10^{6}$ & 3.45 \\
\hline
\end{tabular}
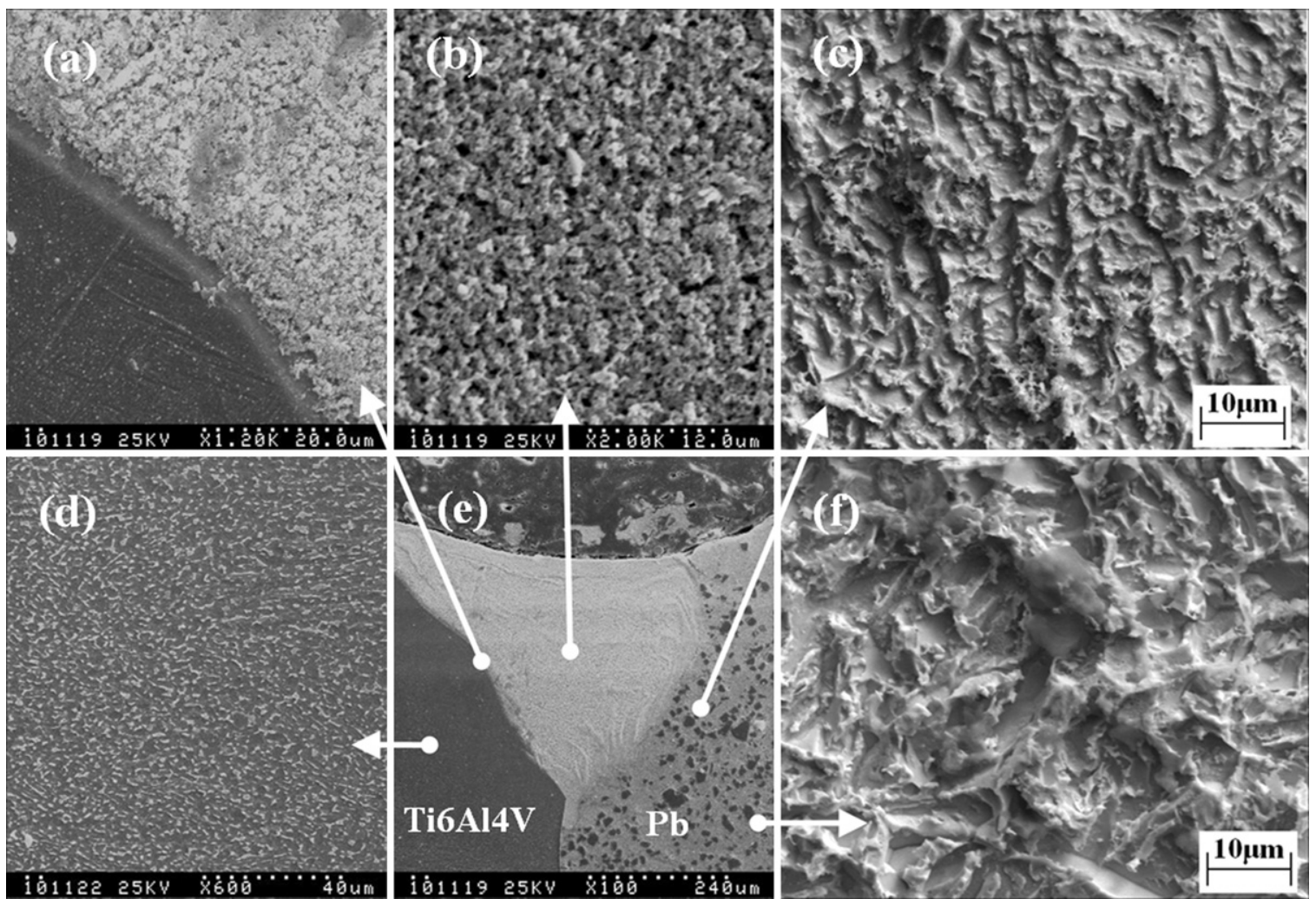

Fig. 4. Microstructure of the weld.
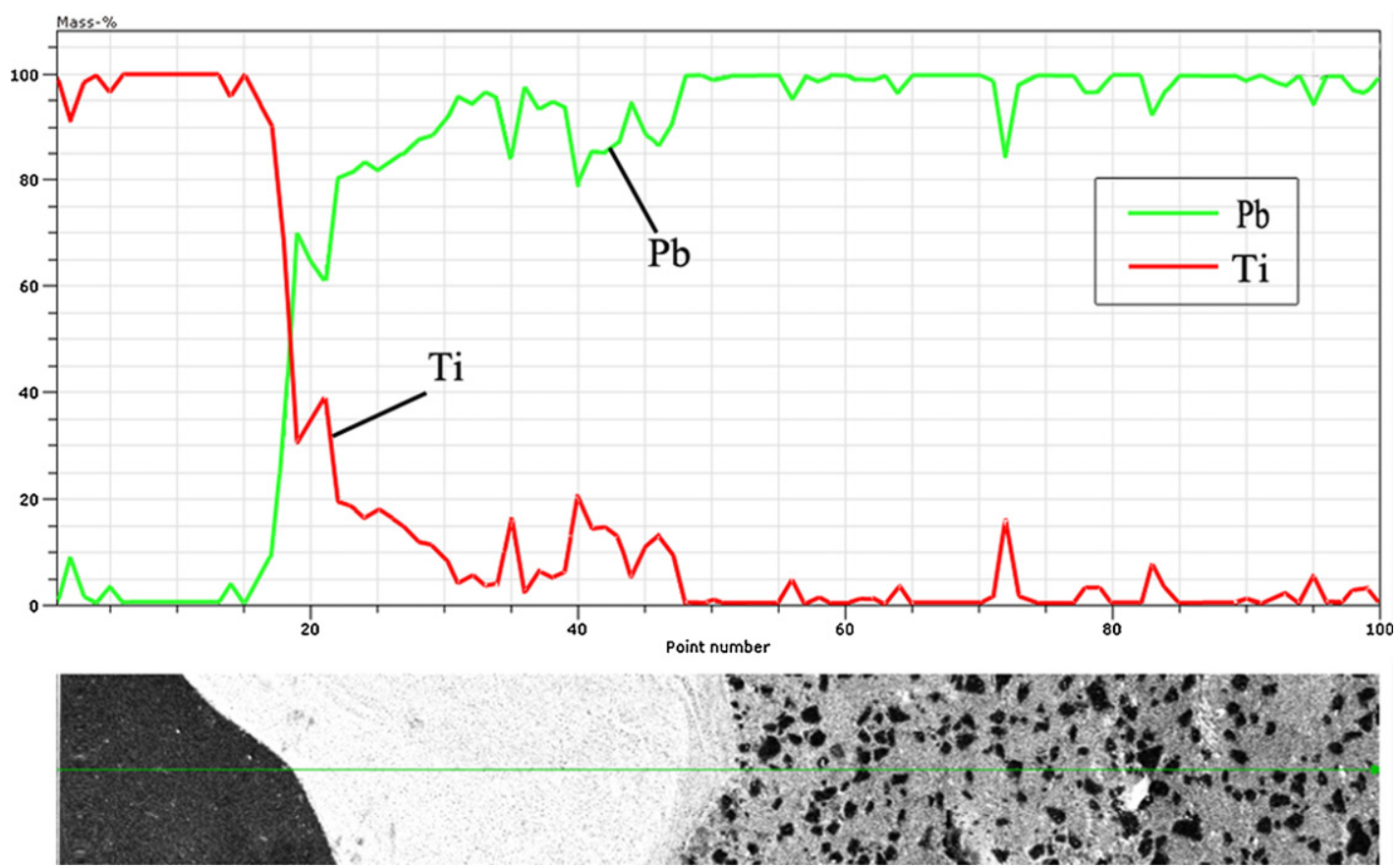

Point number

100 


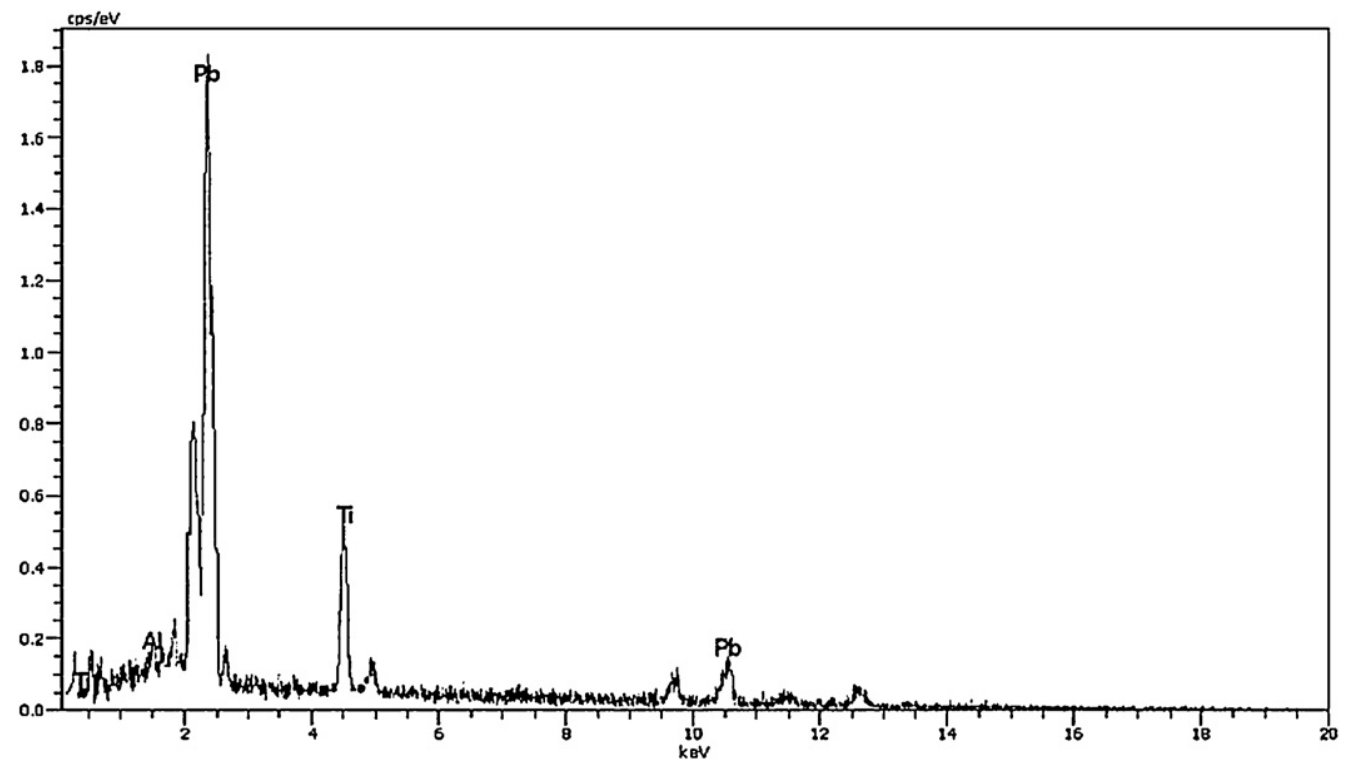

Fig. 6. EDS spectra of the weld.

Table 3

Chemical composition of the weld (wt.\%).

\begin{tabular}{ll}
\hline Element & Mass fraction \\
\hline $\mathrm{Ti}$ & 20.23 \\
$\mathrm{~Pb}$ & 79.31 \\
$\mathrm{Al}$ & 0.46 \\
\hline
\end{tabular}

From the Ti-Pb binary phase diagram, which is characterized by the eutectoid decomposition $(\beta-\mathrm{Ti}) \rightarrow \mathrm{Ti}_{4} \mathrm{~Pb}+(\alpha-\mathrm{Ti})$ at $725^{\circ} \mathrm{C}$, and the peritectic reaction $(\beta-\mathrm{Ti})+\mathrm{L} \rightarrow \mathrm{Ti}_{4} \mathrm{~Pb}$ at $1300^{\circ} \mathrm{C}$, the $\mathrm{Ti}-\mathrm{Pb}$ intermetallic compounds may form at the weld during solidification process. The intermetallic compounds at the weld have been confirmed by X-ray diffraction technique, as presented in Fig. 7. The examination indicated the occurrence of $\mathrm{Ti}-\mathrm{Pb}$ intermetallic compounds $\mathrm{Ti}_{4} \mathrm{~Pb}$.

Laser welding is characterized by extremely high cooling rate (generally of the order $10^{3}-10^{4}{ }^{\circ} \mathrm{C} / \mathrm{s}$ ). Cai et al. (2006) reported that the rapid solidification could refine the microstructure. The microstructure of lead near the white region and lead substrate are shown in Fig. 4(c) and (f), respectively. From the SEM images, the microstructure dimension of lead near white fusion zone was much less than that of lead base metal.

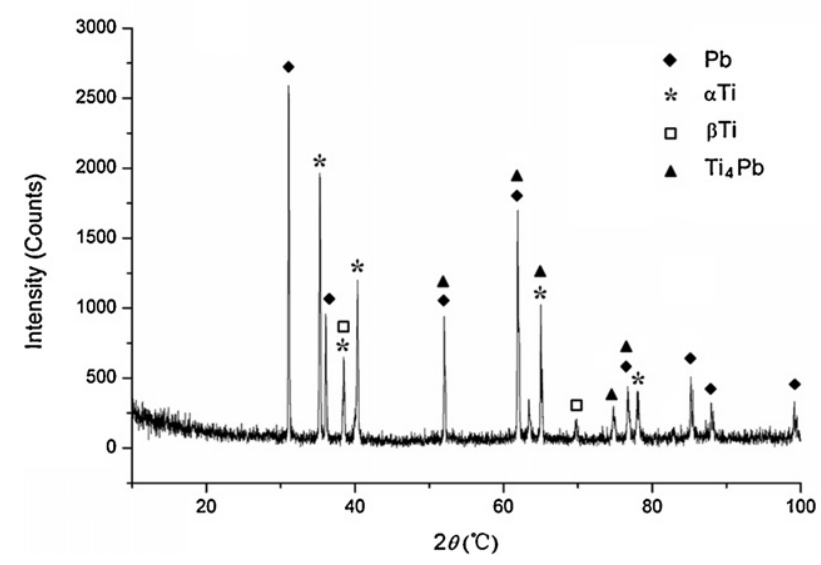

Fig. 7. XRD result of the weld.

\subsection{Hybrid joining mechanism}

Fig. 8 shows the enlarged diagram of different location of the weld shown in Fig. 1(b) and the element distribution for regions $A$ and $B$. It is indicated that both titanium alloy and lead were melted at region A during welding process, there formed a fusion welding seam. The distribution of $\mathrm{Ti}$ and $\mathrm{Pb}$ elements had clear boundary with little element diffusion in region B. It could be inferred that only lead with lower melting point was melted and the titanium alloy remained solid state in region $B$. The liquid lead could wet the surface of the solid Ti6Al4V and formed a brazing seam. For laser welding of dissimilar materials with greatly difference in melting point, region with temperature value higher than melting point of both materials would form a fusion welding seam, and region with temperature between melting point of Ti6Al4V and lead would form a brazing seam. As a result, with appropriate process condition, fusion weld formed at the upper part of the weld and brazing weld with solder of $\mathrm{Pb}$ formed at the lower part of the weld. The weld including fusion welding region and brazing region had adequate welding depth, but also avoids local collapse of lead.

\subsection{Interface formation in molten pool}

Fig. 9 shows macro morphology of the weld with laser power of $400 \mathrm{~W}$, scanning velocity of $20 \mathrm{~mm} / \mathrm{s}$ and laser beam offset of $0.25 \mathrm{~mm}$. Penetration weld was obtained under this process condition. There formed ripples on the top and bottom surface of workpiece, and a collapse at lead side. It is indicated that lead melted with a large volume during welding process due to the low melting point $\left(327^{\circ} \mathrm{C}\right)$. Molten pool was composed of white region and region of melted lead at right side of the white region. Regions of melted lead and lead substrate had similar microstructures except changes in grain size since no high temperature phase produced. As a result, there was no clear interface between regions of melted lead and lead substrate in the weld profile. The chemical composition of $\mathrm{Ti}, \mathrm{Pb}$ and $\mathrm{V}$ were analyzed by EDS surface scan. The white region in Fig. 9(c) was enlarged and shown in Fig. 10. Both $\mathrm{Pb}$ and $\mathrm{Ti}$ elements were detected in the white region and $\mathrm{Ti}$ element was not found in the region of melted lead. Lead could be dissolved in liquid titanium alloy and form a mixed fusion zone, however, Ti element in mixed fusion zone failed to transport to the liquid lead zone. Interface formed in the molten pool. One side of 


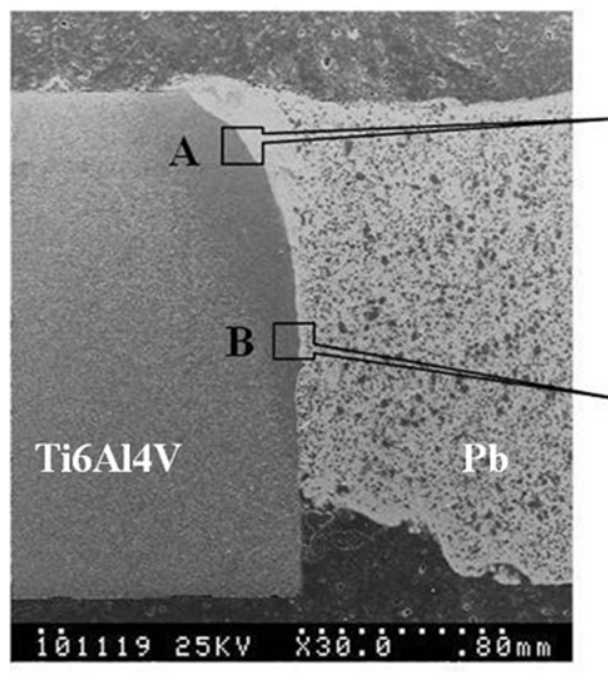

\section{Fusion welding}
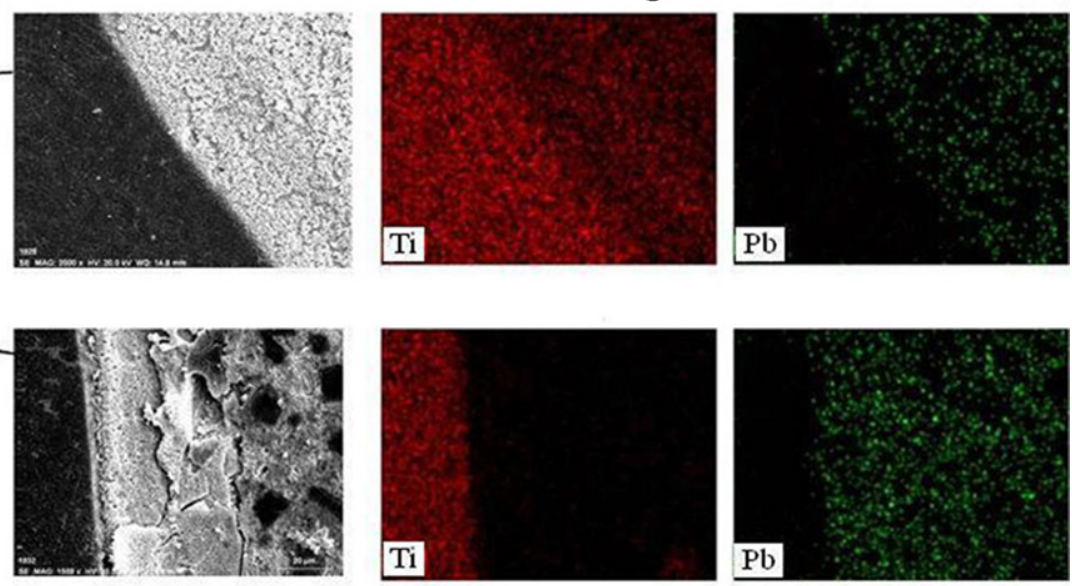

Brazing

Fig. 8. Chemical composition of different regions in a weld.

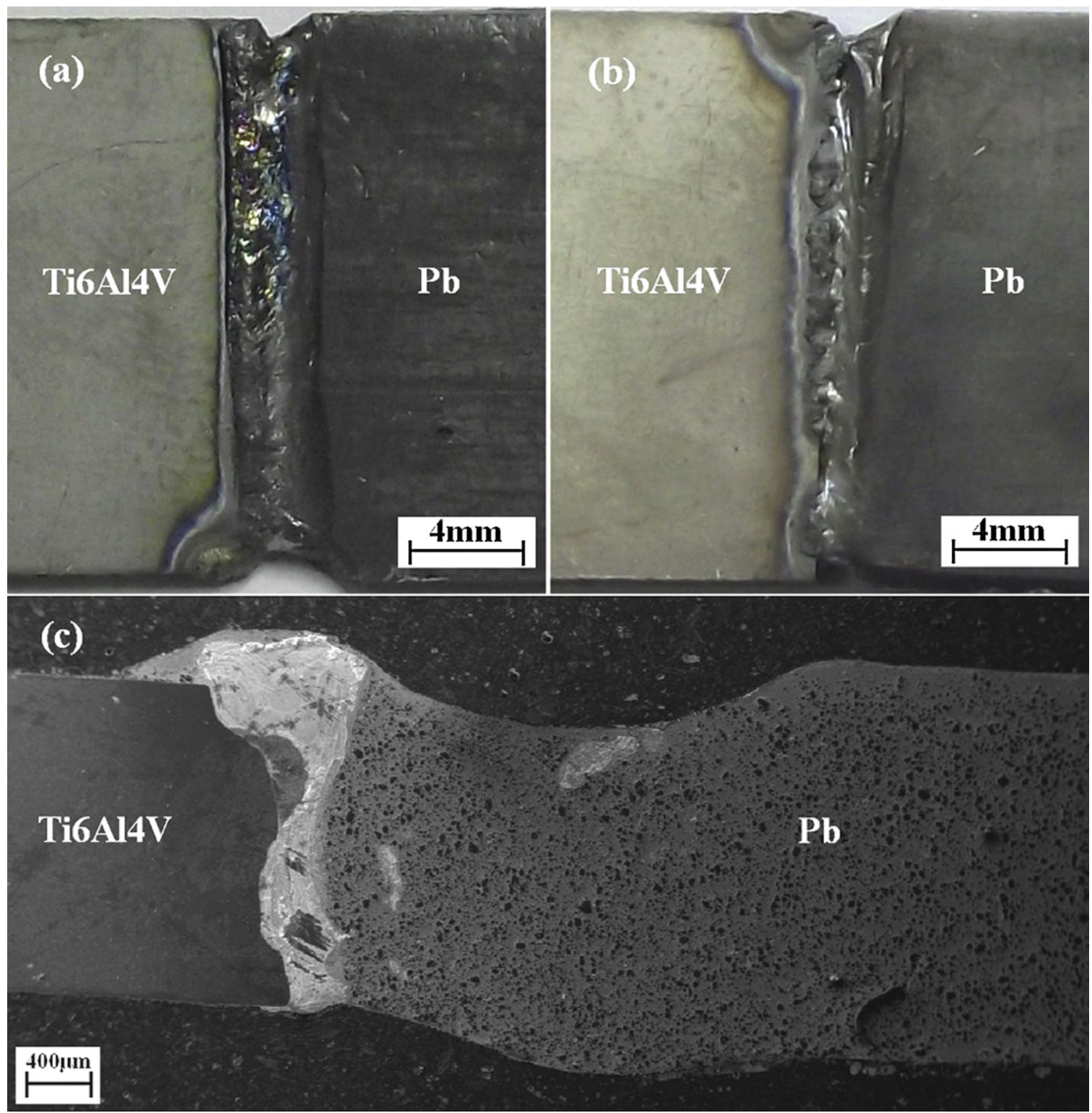

Fig. 9. Profile of the weld: (a) top surface; (b) bottom surface; and (c) macro morphology. 

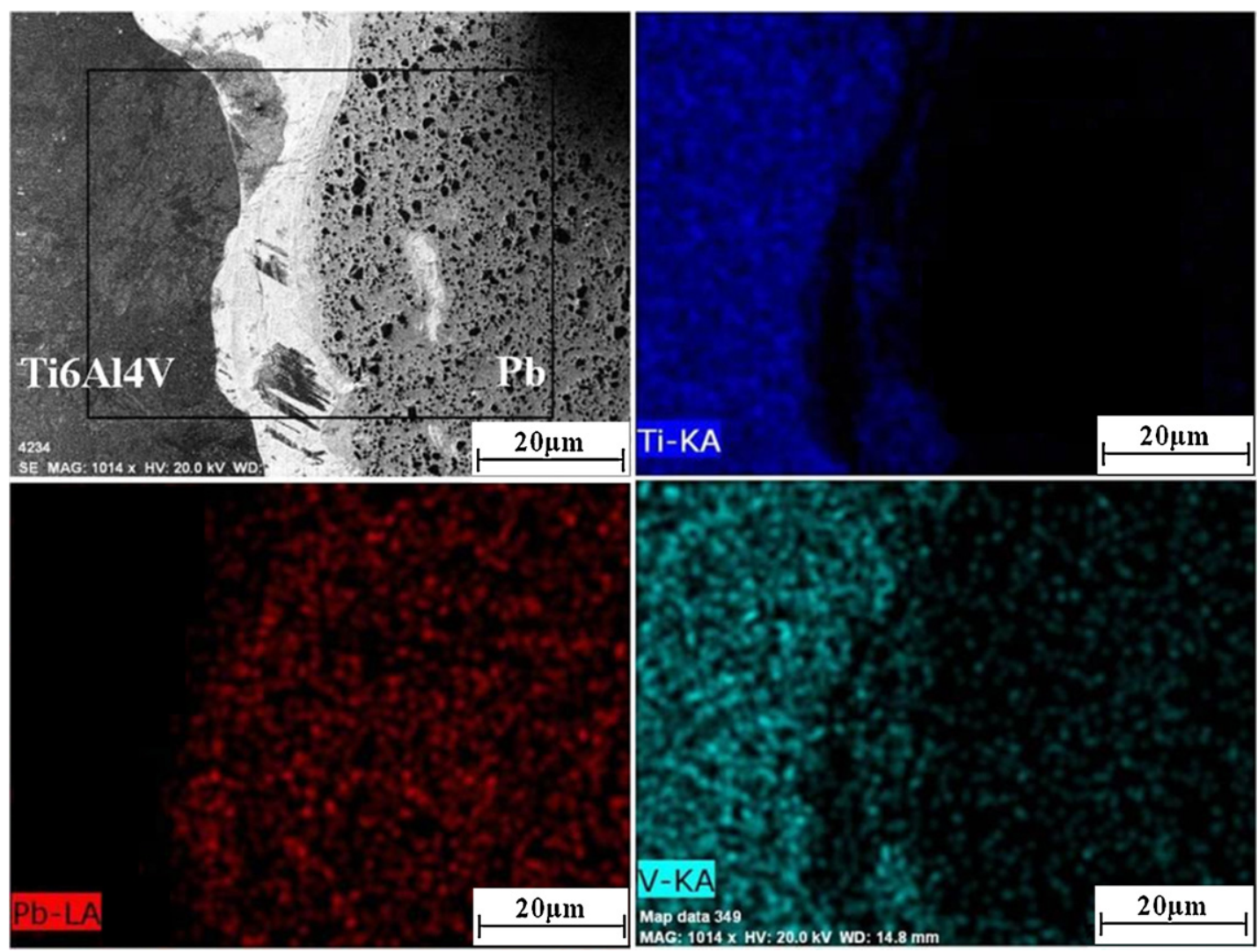

Fig. 10. Distribution of $\mathrm{Ti}, \mathrm{Pb}$, and V elements in the weld.

the interface was the mixed fusion zone containing titanium alloy and lead, the other side was the liquid lead. Similarly, interface formation occurred for other specimens which were characterized by formation of fusion weld.

It could be noted that the surface tension gradients at the top surface (free surface) initiated the convective transport in the molten pool. These surface tension gradients, in turn, were determined by both the temperature and concentration gradients. During welding process, lead was melted to form a molten pool with large dimension firstly, and the temperature of liquid lead varied in the range of melting point to boiling point. Temperature of the zone irradiated by laser beam could reach a value greater than the melting point of base materials instantaneously. Both Ti6Al4V and lead were melted at this zone and formed a mixed fusion zone. Gao et al. (2008) have reported that temperature gradient of the central zone of the molten pool irradiated by laser beam was higher than that of the zone next to the molten pool wall. According to this conclusion, the temperature gradient in mixed fusion zone was much higher than that of the liquid lead zone. Furthermore, concentration gradient of mixed fusion zone was much higher than that of liquid lead zone due to the inhomogeneous element distribution. As the different temperature gradient and concentration gradient, mixed fusion zone and liquid lead zone had different surface tension gradient and driving forces. Besides, Farrar and Margolin (1955) found that the liquid mixture of titanium and lead with above $70 \mathrm{wt} . \%$ $\mathrm{Pb}$ always consolidated into two layers. The outside appeared to be composed entirely of lead and the inside was a Ti-Pb alloy. It was indicated that the solubility of $\mathrm{Ti}$ in liquid $\mathrm{Pb}$ was small. Liquid lead got into the liquid titanium alloy by convection and diffusion to form a mixed fusion zone containing both base materials. Ti element in the mixed fusion zone could not transport to the region of liquid lead due to the solubility gap of Ti in liquid lead. As a result, an interface formed in the molten pool, and one side of the interface contained both $\mathrm{Ti}$ and $\mathrm{Pb}$ elements and the other side of the interface contained only $\mathrm{Pb}$ element.

\subsection{Mechanical properties of the joints}

Fig. 11 shows the microhardness profiles of weld section (with applied load of $0.245 \mathrm{~N}$ and a dwelling time of $15 \mathrm{~s}$ ). The averaged microhardness of mixed fusion zone was $565 \mathrm{HV}$, much higher than that of Ti6Al4V base material (360HV) and lead base material (6HV). These results indicated that the intermetallic compounds might form at the fusion zone. The significant difference in mechanical properties of the mixed fusion zone and lead zone might affect stress state of the joint. Further study is necessary concerning the influence and the corresponding control methods.

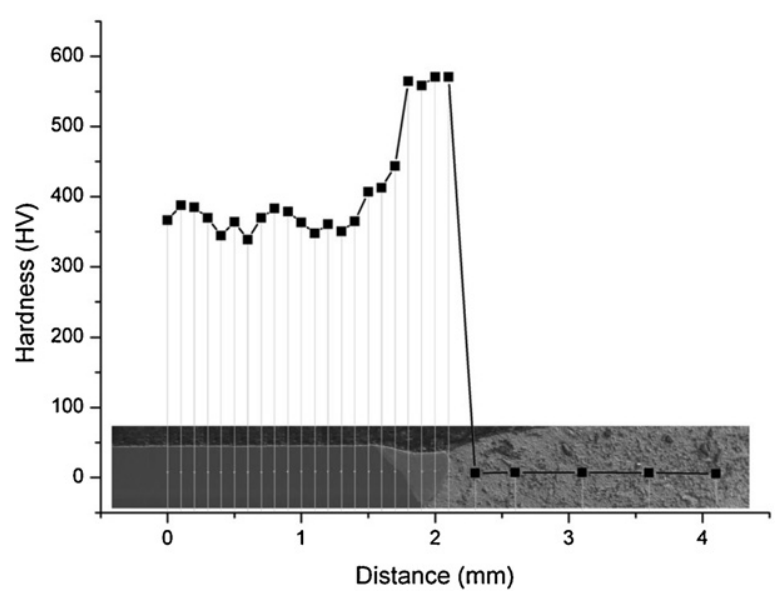

Fig. 11. Microhardness of weld. 
(a)
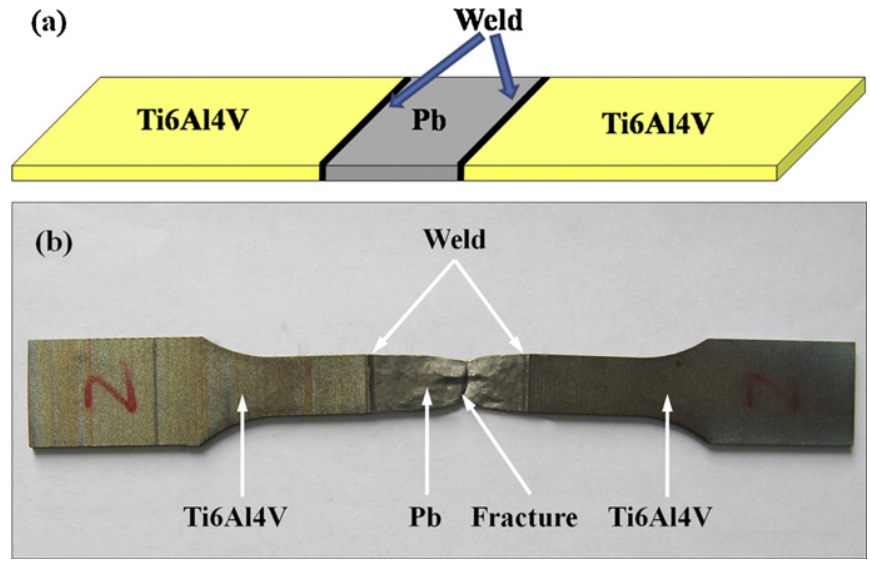

Fig. 12. Schematic diagram of tension specimen (a) and location of fracture during transverse tensile test (b).

Strength of lead material is too low to be clamped on the fixture of tensile testing machine. Specimens with Ti6Al4V-Lead-Ti6Al4V mode were used in the tensile test, i.e. two sheets of Ti6Al4V were welded by laser to two end of the lead substrate, and Ti6Al4V sheets were clamped on the fixture, shown in Fig. 12(a). Two specimens under the same process condition that laser power is $400 \mathrm{~W}$, scanning velocity is $20 \mathrm{~mm} / \mathrm{s}$ and laser beam offset is $0.25 \mathrm{~mm}$ were tested. The results of the joint transverse tensile test showed that the joint fractured in the lead base metal, outside the welded seam shown in Fig. 12(b). Compared to the lead base metal with much lower tensile strength, laser-welded seam was difficult to deform during tension, owing to the alloying of the fusion zone. As a result, the deformation concentrated on the lead base metal and the fracture occurred in the lead base metal. The values of breaking force were $335 \mathrm{~N}$ and $305 \mathrm{~N}$, respectively. The corresponding tensile strength was 13.9 MPa and 12.7 MPa, respectively. The strength of the joint was at least equal to or larger than that of lead base metal, and the fracture surface indicated that lead metal had good ductility.

\section{Conclusion}

Laser dissimilar welding of Ti6Al4V and lead metal was conducted, and further understanding of the welding process was achieved by experimental investigation on microstructural and mechanical characteristics of the joints. The following can be concluded from this work:

(1) Size of the welds is a function of laser beam offset, laser power density, and scanning velocity. With appropriate process condition, fusion weld formed at the upper part of the weld and brazing weld with solder of $\mathrm{Pb}$ formed at the lower part of the weld.

(2) Interface formation in molten pool during laser welding Ti6Al4V and lead was found. The reasons for interface formation may be different driving force of various regions in molten pool due to the different temperature gradient and concentration gradient, and the miscibility gap of Ti and $\mathrm{Pb}$ binary system.

(3) The results of the joint transverse tensile test showed that the joint fractured in the lead base metal, outside the welded seam. Tension strength of the joint was at least equal to or larger than that of lead base metal.

\section{Acknowledgments}

The research was sponsored by National Natural Science of China (Grant Nos. 10832011 and 10972222).

\section{References}

Akman, E., Demir, A., Canel, T., Sinmazcelik, T., 2009. Laser welding of Ti6Al4V titanium alloys. J. Mater. Process. Technol. 209, 3705-3713.

Cai, J., Mac, G.C., Liud, Z., Zhang, H.F., Hu, Z.Q., 2006. Influence of rapid solidification on the microstructure of AZ91HP alloy. J. Alloys Compd. 422, 92-96.

Chakraborty, N., 2009. The effects of turbulence on molten pool transport during melting and solidification processes in continuous conduction mode laser welding of copper-nickel dissimilar couple. Appl. Therm. Eng. 29, 3618-3631.

Chakraborty, N., Chakraborty, S., 2007. Modeling of turbulent molten pool convection in laser welding of a copper-nickel dissimilar couple. Int. J. Heat Mass Transfer. 50, 1805-1822.

Chen, S., Li, L., Chen, Y., Dai, J., Huang, J., 2011. Improving interfacial reaction nonhomogeneity during laser welding-brazing aluminum to titanium. Mater. Des. 32 4408-4416.

Chung, F.K., Wei, P.S., 1999. Mass, momentum, and energy transport in a molten pool when welding dissimilar metals. J. Heat Trans. T. ASME 121, 451-461.

Fabbro, R., Slimani, S., Coste, F., Briand, F., 2005. Study of keyhole behavior for full penetration Nd-Yag CW laser welding. J. Phys. D Appl. Phys. 38, 1881-1887.

Farrar, P., Margolin, H., 1955. Titanium-lead system. J. Met. 7, 101-104.

Gao, M., Zeng, X.Y., Yan, J., Hu, Q.W., 2008. Microstructure characteristics of laserMIG hybrid welded mild steel. Appl. Surf. Sci. 254, 5715-5721.

Grigor'yants, A.G., 1987. Special features of laser welding an aluminum alloy to lead. Weld. Int. 1, 455-456.

Kreimeyer, M., Florian Wagner, F., Vollertsen, F., 2005. Laser processing of aluminum-titanium-tailored blanks. Opt. Laser Eng. 43, 1021-1035.

Phanikumar, G., Dutta, P., Chattopadhyay, K., 2004. Computational modeling of laser welding of Cu-Ni dissimilar couple. Metall. Mater. Trans. B 35, 339-350.

Phanikumar, G., Dutta, P., Chattopadhyay, K., 2005a. Continuous welding of $\mathrm{Cu}-\mathrm{Ni}$ dissimilar couple using $\mathrm{CO}_{2}$ laser. Sci. Technol. Weld. Join. 10, 158-166.

Phanikumar, G., Manjini, S., Dutta, P., Mazumder, J., Chattopadhyay, K., 2005b. Characterization of a continuous $\mathrm{CO}_{2}$ laser-welded $\mathrm{Fe}-\mathrm{Cu}$ dissimilar couple. Metall. Mater. Trans. A 36, 2137-2147.

Tomashchuk, I., Sallamand, P., Jouvard, J.M., Grevey, D., 2010. The simulation of morphology of dissimilar copper-steel electron beam welds using level set method. Comp. Mater. Sci. 48, 827-836.

Zhao, S.S., Yu, G., He, X.L., Zhang, Y.J., Ning, W.J., 2011. Numerical simulation and experimental investigation of laser overlap welding of Ti6Al4V and 42CrMo. J. Mater. Process. Technol. 211, 530-537. 